\title{
BMJ Open Pathways connecting socioeconomic variables, substance abuse and gambling behaviour: a cross-sectional study on a sample of Italian high- school students
}

\author{
Alessandra Buja (D , ${ }^{1}$ Claudia Mortali, ${ }^{2}$ Luisa Mastrobattista ${ }^{2}$ Adele Minutillo, ${ }^{2}$ \\ Simona Pichini, ${ }^{2}$ Bruno Genetti, ${ }^{3}$ Paolo Vian, ${ }^{3}$ Alessandra Andreotti, ${ }^{3}$ \\ Giulia Grotto (1) , ${ }^{1}$ Vincenzo Baldo, ${ }^{1}$ Roberta Pacifici ${ }^{2}$
}

To cite: Buja A, Mortali C, Mastrobattista L, et al. Pathways connecting socioeconomic variables, substance abuse and gambling behaviour: a cross-sectional study on a sample of Italian high-school students. BMJ Open 2019;9:e031737. doi:10.1136/ bmjopen-2019-031737

- Prepublication history for this paper is available online. To view these files, please visit the journal online (http://dx.doi. org/10.1136/bmjopen-2019031737).

Received 16 May 2019 Revised 03 September 2019 Accepted 16 September 2019

Check for updates

(c) Author(s) (or their employer(s)) 2019. Re-use permitted under CC BY-NC. No commercial re-use. See rights and permissions. Published by BMJ.

${ }^{1}$ Department of Cardiological, Thoracic, Vascular Sciences and Public Health, University of Padua, Padova, Italy

${ }^{2}$ Centro Nazionale Dipendenze e Doping, Istituto Superiore di Sanità, Roma, Italy

${ }^{3}$ Explora Center for Research and Statistical Analysis, Vigodarzere, Italy

Correspondence to Dr Alessandra Buja; alessandra.buja@unipd.it

\section{ABSTRACT}

Objectives The aim of this study was to elucidate the pathway of associations linking gambling, alcohol intake, smoking habit, cannabis consumption between each other and with demographic and socioeconomic variables. Setting and participants A survey was conducted in 2017 on a representative sample of 15602 Italian 14-yearolds to 17-year-olds attending 201 secondary schools.

Outcome measures Structural Equation Models analysis was used to assess the pathway between gambling, alcohol intake, smoking, cannabis consumption, demographics and socioeconomic factors.

Results Irrespective of socioeconomic or demographic variables, gambling is positively associated with alcohol and cannabis consumption, while cannabis consumption is predicted by smoking and by alcohol intake, smoking is predicted by alcohol intake. Adolescents with a higher weekly income are more at risk of gambling, drinking alcohol and smoking, while the degree of economic dissatisfaction was positively associated with alcohol intake, cannabis consumption and smoking. Maternal employment appeared to be positively associated with adolescents' smoking, alcohol intake and cannabis consumption.

Conclusions This is one of the first studies to shed light on the pathways of associations connecting various health-risk behaviours among adolescents with demographic and socioeconomic factors.

\section{INTRODUCTION}

In the last decade, problem gambling, alcohol consumption and substance abuse among adolescents has emerged as a growing public health issue. ${ }^{12}$ Further, gambling disorder has been reclassified as an addiction and related disorder alongside alcohol and other substance use disorders. ${ }^{3}$

Adolescence is a developmental stage in which addictions can develop when the experimental use of alcohol, tobacco and drug turns into patterns of regular substance

\section{Strengths and limitations of this study}

- Data were obtained from a sample of adolescents attending school, so the study sample is only representative of Italian school students. This means that adolescents who dropped out of school at 16 years old (on completing their compulsory education in Italy) were not considered.

- Self-reports data were collected which could be biased by under-reporting of respondents about their risk-taking behaviour; to mitigate this potential bias, we guaranteed respondents' anonymity and confidentiality.

- Path analysis enables the simultaneous estimation of several associated regression showing interrelation through which independent variables produce both direct and indirect effects on more than one dependent variable; both the magnitude and the significance of associations between variables were estimated.

use. ${ }^{4}$ Previous studies found that pathological gambling was often associated with alcohol, nicotine and substance dependence, suggesting that each of these types of behaviours may serve as a primer for the others. $^{6-9}$ Other investigations suggested that acute alcohol ingestion may increase the propensity to gamble soon afterwards. ${ }^{10}$

Just as various types of substance abuse act as a gateway to others, the literature has demonstrated that different substance abuse risk factors seem to overlap in their association with adolescents' health-risk behaviours. Specific to adolescent development, for example, is the correlation between parents' low socioeconomic status (SES) and the risk of problem behaviour in their adolescent offspring, ${ }^{11}$ whereas higher household 
incomes seem to be protective, possibly due to their linkage with positive parenting styles and advantaged life circumstances. ${ }^{12}$ Problem gambling also seems to be more common in the low SES population. ${ }^{13}$

Several studies have investigated the association between substance abuse or gambling risk factors-including socioeconomic characteristics such as male gender, young age, neighbourhood disadvantage and low $\mathrm{SES}^{14-16}$-and specific types of health-risk behaviour, such as alcohol drinking, cigarette smoking and illicit substance use. ${ }^{15} 1718$ To our knowledge, however, no prior research has sought at the same time to examine the potential explanatory pathway between the former major risk factors and the latter health-risk behaviours. Hence, our interest in investigating how the relationships between SES and health-risk behaviours drive towards the development of gambling behaviour in adolescence.

In an attempt to shed light on these associations between SES, substance abuse and gambling behaviour, we simultaneously considered the multiple potential pathways between gambling, alcohol intake, smoking habit, cannabis consumption and socioeconomic variables, drawing on data from a large representative population of Italian high-school students.

\section{METHODS}

The sample population was drawn from the 'Gambling in Italy' project, a student population survey conducted in 2017 by the Istituto Superiore di Sanità. For the purposes of the present study, the survey is briefly described below.

\section{Study sample}

The sample refers to the Italian student population between 14 and 17 years of age, taking into account the population's geographical distribution nationwide in order to intercept metropolitan, urban and suburban areas. The sampling method followed a three-stage Probability Proportional to Size model, where the first-stage units were represented by the cities, the second-stage units by the schools and the third-stage units by the classes. The sampling design involved stratifying the firststage, second-stage and third-stage units as follows. In each stratum: the first-stage units (cities) were selected with probabilities proportional to the number of upper secondary school classes within the territory of the cities; the second-stage units (schools) were selected with probabilities proportional to the number of classes in the sample schools and the third-stage units (classes) were selected in the same numbers for each school in the stratum to which they belonged. All students attending the sample classes were included in the sample. Using this sampling method meant that the probability of each class and each student in the target population being selected remained constant.

The survey was conducted using a Computer-Assisted Self-Interview method that enabled the questionnaire to be completed by students online using a non-replicable, unique and anonymous access ID. Students accessed the questionnaire using a link provided by the technicians in the schools' computer rooms.

A total of 201 schools (187 public, 14 private) took part in the survey, and 859 classes were sampled, accounting for a student population of 18042. A total of 17610 online questionnaires were completed at school by the students who agreed to participate in the survey. Six questionnaires were rejected because they were answered by students not resident in Italy (step 1); 267 were rejected because they were incomplete (step 2); another 1504 were rejected because they were answered by students outside the age group considered in the survey (ie, under 14 or over 17 years old) (step 3) and 231 were rejected because they contained answers judged scarcely plausible (unreliable or irrelevant responses were identified by means of a Rasch analysis; step 4). Thus, a final number of 15602 questionnaires $(88.6 \%$ of the total) were considered eligible for this study.

\section{Patient and public involvement}

No patients were involved in this study.

\section{Variables}

The demographic variables considered were age bracket (14-15 years, $16-17$ years) and sex.

The questionnaire examined respondents' SES and social environment by means of questions on: highest education level attained by parents (both with a university degree, one with a university degree, at least one with a high-school diploma, both with an elementary or middleschool diploma); maternal employment (not working, working); paternal employment (not working, working); level of economic dissatisfaction (very satisfied/satisfied, neither satisfied nor dissatisfied, dissatisfied/very dissatisfied); amount of weekly pocket money (€0, €1-30, $€ 31-100, € 100$ or more); parental death (both parents alive, at least one parent deceased).

We also categorised the geographical area (CentralNorthern Italy/Southern Italy and Islands) and considered the type of high school attended (vocational technical/professional schools/scientific/artistic grammar schools).

The SOGS-RA scale ${ }^{19} 20$ was used to examine respondents' gambling behaviour. This validated tool contains 12 items and generates scores that range from 0 to 12 . It measures several aspects, such as loss of control over the game, action taken to recover monetary losses, interference with family, school and relational life, guilt feelings about money spent and consequences of gambling. To be defined as 'gamblers', respondents only had to report having been involved in a gambling activity at least once in the previous year. Then, the SOGS-RA scale identifies three types of 'gambler': non-problem (SOGS-RA score $=0$ 1); at risk (SOGS-RA=2-3) and problem (SOGS-RA score higher than 4). Students who reported having no experience of gambling in the previous year were defined as 'non-gamblers'. For the purpose of this study, the variable 
assessing gambling behaviour was divided into two categories: non-gamblers and non-problem gamblers versus at risk and problem gamblers.

Respondents were also questioned about their riskrelated substance use: smoking (never in the previous year/at least once in the previous year), cannabis consumption (never in the previous year/at least once in the previous year) and intake of alcoholic drinks, that is, beer, wine, cocktails, spirits (never in the previous month/at least once in the previous month).

\section{Statistical analysis}

Previous studies found that people who gambled also tended to have problems with substance abuse, ${ }^{21}$ and that certain sociodemographic factors were shared with determinants of these health-risk behaviours. No studies currently available in the literature have considered a broader framework, however, to test for the existence of a comprehensive structure of associations. We use a path analysis to test these associations. Such an approach can be useful in planning multi-component public healthcare and prevention programmes. Given the large sample size, Bernoulli's simple random sampling method was adopted. A bivariate analysis was run on each of the above-described variables and gambling status. A set of Pearson's $\chi^{2}$ tests was used to highlight any associations between each health-risk behaviour (gambling, alcohol consumption, smoking and cannabis use) and the demographic and socioeconomic variables (sex, age bracket, weekly income, level of economic dissatisfaction, paternal education, maternal employment, paternal employment, death of a parent, type of school and geographical area).

Path analysis via multiple regression was used to test causal models by examining the relationships between a dependent variable and independent variables. This enabled the simultaneous estimation of several associated regression relationships. In this analysis, a variable could be a dependent variable in one relationship and an independent variable in another. This method enables both the magnitude and the significance of causal connections between variables to be estimated, ${ }^{22}$ showing causal mechanisms through which independent variables produce both direct and indirect effects on a dependent variable.

The path analysis model was estimated using Mplus software, release $5.21 .^{22}$ To estimate the path coefficients, Mplus used ordinary least squares (OLS) and maximum likelihood methods. The statistics used to test the significance and goodness of fit of the model were: the root mean square error of approximation (lower than 0.08 for a goodness of fit model), the Comparative Fit Index (higher than 0.90 for a goodness of fit model) and the Tucker Lewis index (higher than 0.90 for a goodness of fit model). ${ }^{23}$

\section{RESULTS}

Of the 15602 questionnaires analysed, $50.9 \%$ were answered by females, and the mean age of respondents was 15.53 years $( \pm 1.11 \mathrm{SD})$. The prevalence of at-risk/ problem gamblers was $6.5 \%$ (CI 6.1 to 6.9 ). As for the other behaviours considered, $45.4 \%$ (CI 44.6 to 46.2) of the students had had at least one alcoholic drink in the previous month, $25.6 \%$ (CI 24.9 to 26.3 ) had smoked at least once in the previous year and $18.1 \%$ (CI 17.5 to 18.7) had consumed cannabis at least once in the previous year.

Table 1 shows the study sample's characteristics. Table 2 shows the bivariate associations between the sociodemographic characteristics and the health-risk behaviours. Table 3 shows the bivariate associations between different health-risk behaviours. Figure 1 shows the pathway analysis.

Irrespective of the socioeconomic and demographic variables, gambling was positively associated with alcohol and cannabis consumption, while cannabis consumption was predicted by smoking and alcohol intake and smoking was predicted by alcohol intake. As regards the demographic factors, the pathway identified shows that males were more at risk of being involved in all the health-risk behaviours considered in this study except for smoking, while females seemed more likely to smoke. As for the socioeconomic factors, adolescents with a higher weekly income were at greater risk of gambling, drinking alcohol and smoking, while the degree of economic dissatisfaction was positively associated with alcohol intake, cannabis consumption and smoking. Maternal employment seemed to be positively associated with adolescents' smoking, alcohol intake and cannabis consumption. Adolescents with better-educated parents were also at higher risk of drinking alcohol and consuming cannabis. Analysing the geographical distribution of the different health-risk behaviours, it emerged that gambling was more common in Southern than in Central and Northern Italy, whereas cannabis consumption was more common among adolescents in the centre and north of the country. When the prevalence of health-risk behaviour was examined by type of school, it emerged that the vocational technical/professional school students were more at risk of gambling, smoking and consuming alcohol, whereas cannabis consumption was higher at scientific/artistic grammar schools. Last, respondents who reported having a deceased parent were more likely to be smokers.

\section{DISCUSSION}

The present study illustrates the pathway linking healthrisk behaviours with demographic and socioeconomic factors. The findings indicate that nearly one in two underage school students had had at least one alcoholic drink in the previous month, that one in four smoked, nearly 1 in 5 had consumed cannabis in the previous year and 1 in 15 could be defined as an at risk or problem gambler. These prevalence data are consistent with previous research. ${ }^{24}$ The particular geographical distribution of the ORs for the prevalence of different health-risk behaviours in Italy was also in line with official records..$^{2526}$ 


\begin{tabular}{|c|c|c|}
\hline Variables & Categories & $\mathbf{N}(\%)$ \\
\hline \multirow[t]{2}{*}{ Gender } & Females & 7940 (50.9) \\
\hline & Males & $7662(49.1)$ \\
\hline \multirow[t]{2}{*}{ Age bracket } & $14-15$ years & $7622(48.9)$ \\
\hline & $16-17$ years & $7980(51.1)$ \\
\hline \multirow[t]{2}{*}{ Gambling } & $\begin{array}{l}\text { Non-gambler+non-problem } \\
\text { gamblers }\end{array}$ & $14590(93.5)$ \\
\hline & At risk+problem gamblers & $1012(6.5)$ \\
\hline \multirow[t]{2}{*}{ Alcohol intake } & Never in the last year & $8522(54.6)$ \\
\hline & At least once last year & $7080(45.4)$ \\
\hline \multirow[t]{2}{*}{ Smoking } & Never in the last year & $11613(74.4)$ \\
\hline & At least once last year & $3989(25.6)$ \\
\hline \multirow{2}{*}{$\begin{array}{l}\text { Cannabis } \\
\text { consumption }\end{array}$} & Never in the last year & $12780(81.9)$ \\
\hline & At least once last year & $2822(18.1)$ \\
\hline \multirow[t]{4}{*}{$\begin{array}{l}\text { Parents' } \\
\text { education }\end{array}$} & $\begin{array}{l}\text { Both with high-school diploma or } \\
\text { university degree }\end{array}$ & $7615(51.7)$ \\
\hline & $\begin{array}{l}\text { At least one with university } \\
\text { degree }\end{array}$ & $712(4.8)$ \\
\hline & $\begin{array}{l}\text { At least one with high-school } \\
\text { diploma }\end{array}$ & $3477(23.6)$ \\
\hline & $\begin{array}{l}\text { Both with elementary or middle- } \\
\text { school diploma }\end{array}$ & $2930(19.9)$ \\
\hline \multirow{2}{*}{$\begin{array}{l}\text { Mother's } \\
\text { employment }\end{array}$} & Not working & $4670(30.4)$ \\
\hline & Working & $10717(69.6)$ \\
\hline \multirow{2}{*}{$\begin{array}{l}\text { Father's } \\
\text { employment }\end{array}$} & Not working & $1119(7.4)$ \\
\hline & Working & $13987(92.6)$ \\
\hline \multirow{2}{*}{$\begin{array}{l}\text { Deceased } \\
\text { parents }\end{array}$} & Both parents alive & $15311(98.1)$ \\
\hline & At least one deceased parent & $291(1.9)$ \\
\hline \multirow{3}{*}{$\begin{array}{l}\text { Level of } \\
\text { economic } \\
\text { dissatisfaction }\end{array}$} & Very satisfied or satisfied & $10319(66.1)$ \\
\hline & Neither satisfied nor dissatisfied & 4508 (28.9) \\
\hline & Dissatisfied or very dissatisfied & $775(5)$ \\
\hline Weekly income & 0 & $2882(18.5)$ \\
\hline
\end{tabular}

$(€)$

\begin{tabular}{|c|c|c|}
\hline & $1-30$ & $10798(69.2)$ \\
\hline & $31-100$ & 1599 (10.2) \\
\hline & 100 or more & $323(2.1)$ \\
\hline \multirow{3}{*}{$\begin{array}{l}\text { Geographical } \\
\text { area }\end{array}$} & Northern Italy & 6543 (41.9) \\
\hline & Central Italy & $2923(18.7)$ \\
\hline & Southern Italy and Islands & $6136(39.3)$ \\
\hline \multirow[t]{2}{*}{ Type of school } & $\begin{array}{l}\text { Grammar school or artistic high } \\
\text { school }\end{array}$ & $8071(51.7)$ \\
\hline & Technical or vocational school & $7531(48.3 \%$ \\
\hline
\end{tabular}

On the associations between different types of healthrisk behaviour, this study highlighted that gambling is associated with alcohol and cannabis consumption, even after controlling for socioeconomic and demographic factors. The higher prevalence of multiple healthrisk behaviours among young gamblers is a commonly recognised problem. ${ }^{27}$ For instance, data from a US sample of 2274 young people aged 14-21 years showed that alcohol, tobacco and marijuana use and conduct disorder are strong independent predictors of gambling. ${ }^{27}$ This supports the concept that substance abuse and gambling behaviour are part of a more general problem behaviour syndrome associated with conduct disorder. ${ }^{27}$ This concept suggests that, as one type of adolescent problem behaviour increases, the likelihood of other problem behaviours developing increases too, and the co-occurrence of problem behaviours suggests that they have antecedent explanatory factors in common. ${ }^{27}$ The tendency of some adolescents to adopt multiple healthrisk behaviours could be explained by the 'gateway hypothesis', ${ }^{28} 29$ according to which an adolescent's early experimentation with alcohol or tobacco or cannabis can escalate to more addictive illicit drug use. ${ }^{30}$

As regards the economic factors, a higher weekly income was positively associated with all the health-risk behaviours considered in this study, with the exception of cannabis consumption. Consistently with this finding, a New Zealand survey on a sample of secondary school students of the same age as our sample (14-17 years old) revealed that the proportion of students with part-time jobs, and consequently more money, was associated with a greater consumption of alcohol, cigarettes and gambling. ${ }^{31}$ These results suggest that having access to more money could increase an adolescent's chances of engaging in health-risk behaviours. ${ }^{31}$ In fact, previous research found that demand for substances is price-sensitive: ${ }^{32} 33$ following the demand model for goods and services, adolescents with higher disposable incomes could also be at higher risk of substance use because they have more financial resources to purchase alcohol ${ }^{34}$ or other addictive substances. ${ }^{35} 36$ It would be worth considering intervention designed to provide young people with guidance on the use of their discretionary income,${ }^{31}$ alongside approaches that steer parents to limit the amount of money they give to their children unless they have a clear picture of how it is being spent.

Our study also revealed that economic dissatisfaction was associated with alcohol, smoking and cannabis use, but not with gambling behaviour. In line with our results, a meta-analysis ${ }^{37}$ on marijuana and alcohol use by SES in adolescents aged 10-15 years found that the prevalence of marijuana and alcohol consumption was $22 \%$ higher in adolescents with a lower SES than in those with a higher SES. A possible explanation for this could come from strain theory, ${ }^{38}$ according to which coming from a relatively poor family (like failing at school) can be as a source of dissatisfaction that promotes potential healthrisk behaviour, including substance use, as a way to gain respect when ordinary social valuations are impossible. ${ }^{39}$ In the light of these findings, it would be desirable for public health prevention strategies to focus most on the more deprived populations in order to prevent the 


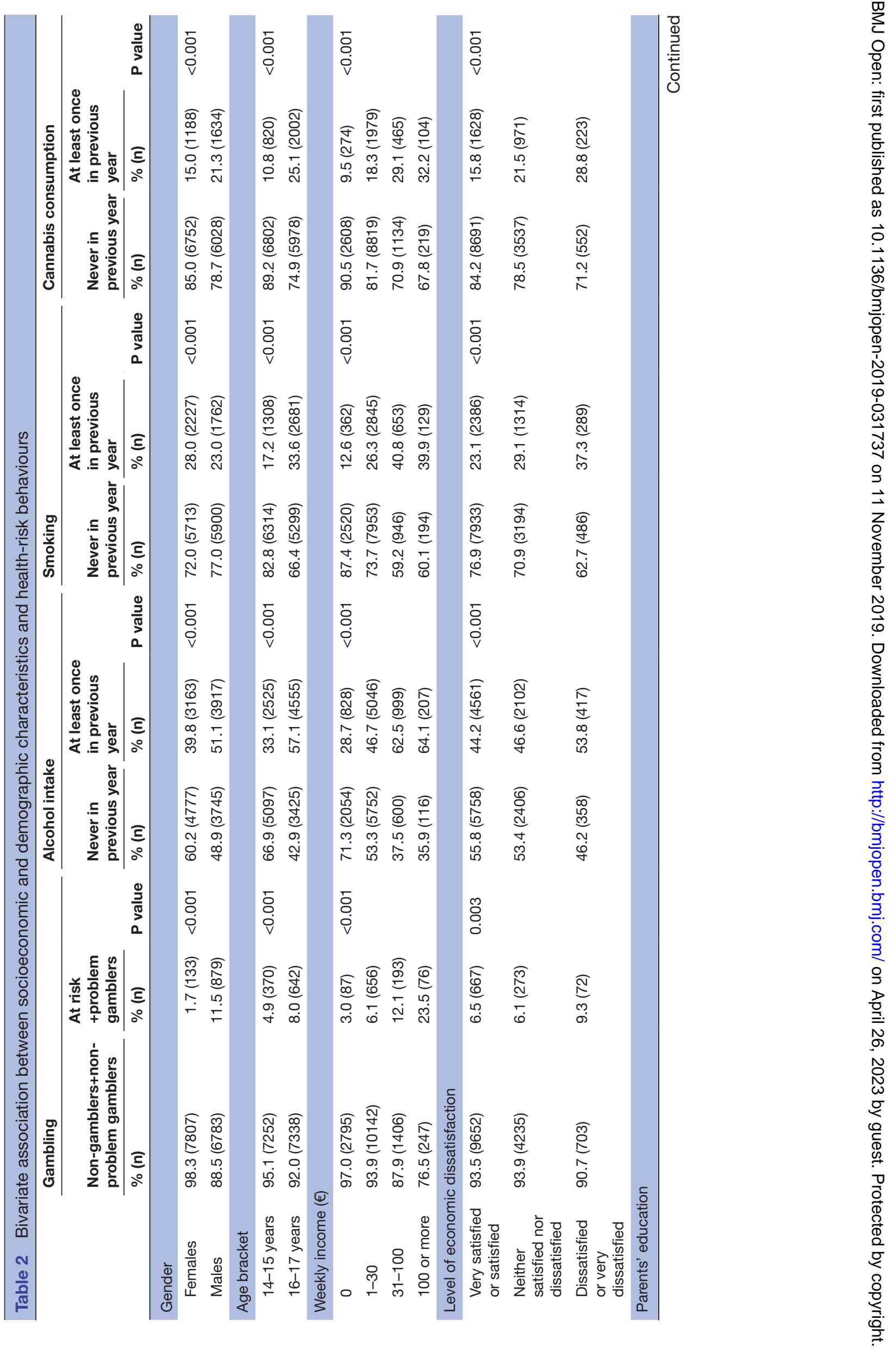




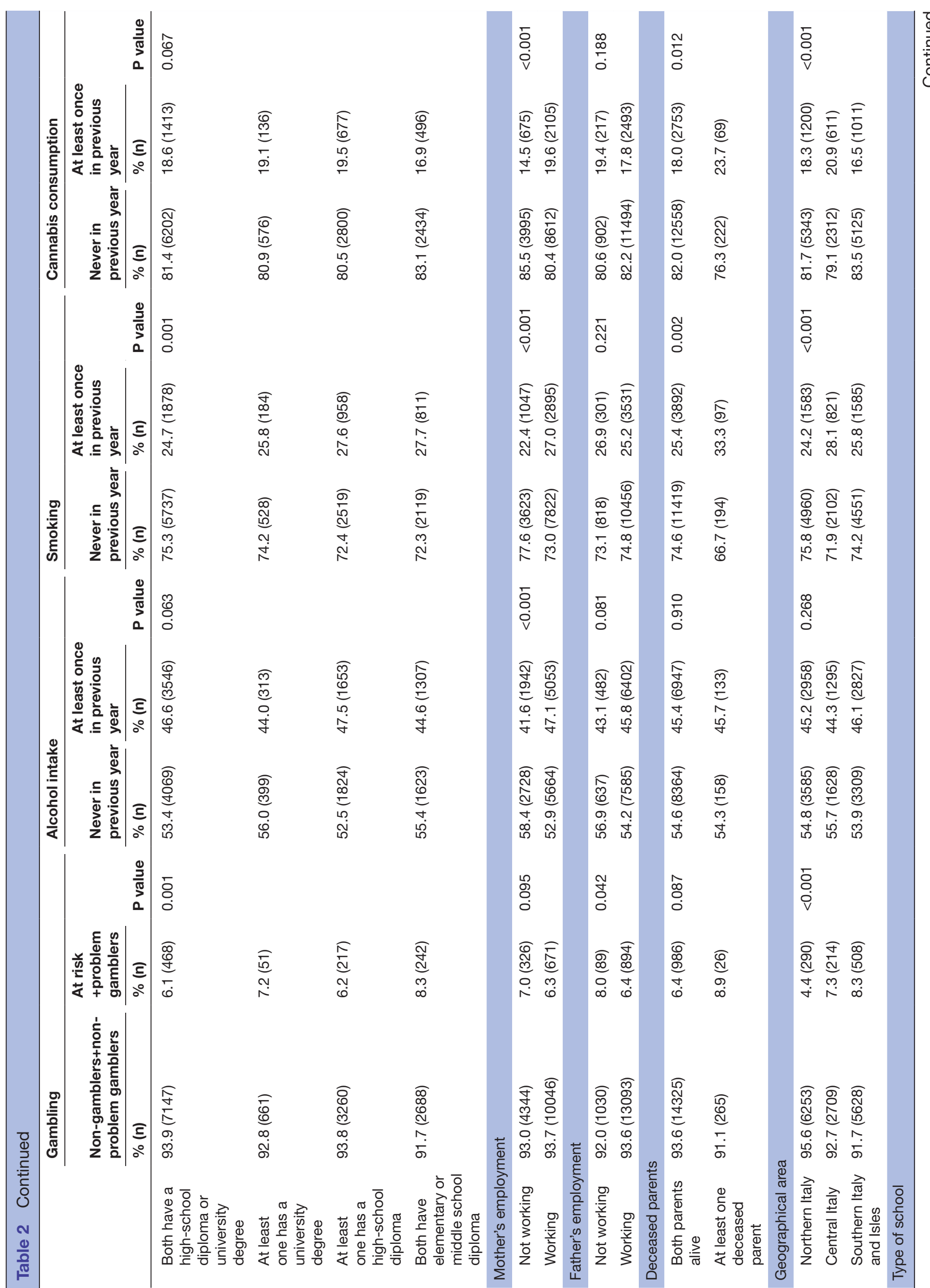




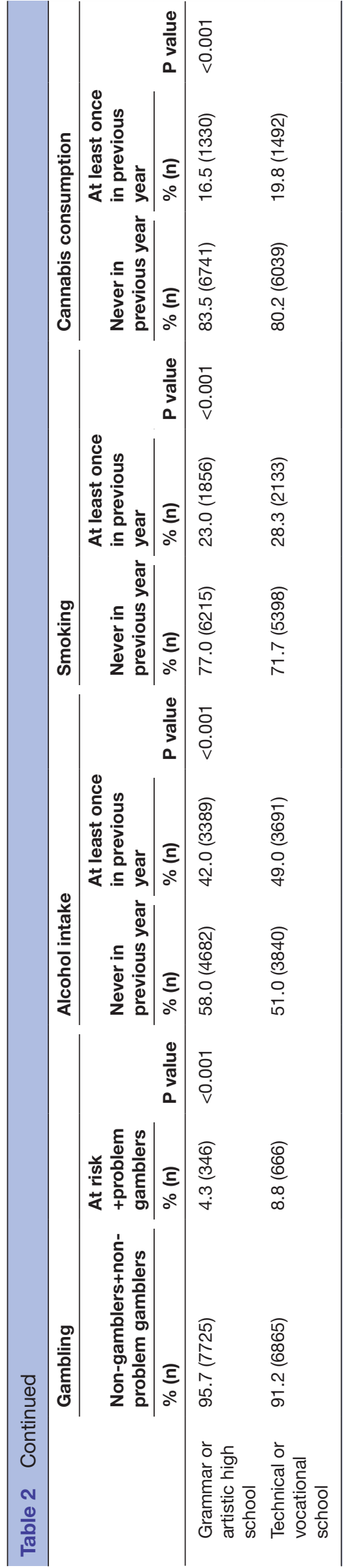

spread of social inequalities, which might even be further aggravated by untargeted prevention schemes.

As for the social context, this study found maternal employment positively associated with alcohol and cannabis consumption and smoking in adolescence. A possible explanation for this could lie in that working mothers generally spend less time at home and might monitor their children less effectively. Previous studies have shown an increased risk of tobacco and alcohol use among adolescents who experience less parental supervision due to their absence from home. ${ }^{40}$ In fact, parental monitoring, which incorporates parent-youth communication, and youth supervision by parents or guardians, seems to be especially influential in its association with adolescent involvement in health-risk behaviours, both delaying the onset of such behaviours among naive adolescents, and containing them among adolescents already practicing them. ${ }^{41} 42$

Our study highlighted a major risk of smoking in adolescents who had experienced a parent's death. Other authors ${ }^{43}$ examined the impact of exposure to family adversity (including parental death, parental conflict, parental absence from home and divorce) on the timing of smoking initiation, using data from a longitudinal panel study. The four types of family adversity examined were all associated with a higher risk of smoking, but losing a parent had the greatest impact on the initiation of smoking. There is substantial evidence of these adverse experiences having a deleterious impact on a child's developmental, behavioural, psychosocial and physical outcomes. ${ }^{44}$ Adolescents, in particular, may try substance use in an effort to cope with their stress, as posited by stress-coping theory. ${ }^{45}$ In parallel, social learning theory suggests that people who face more adversity tend to have parents or close friends who are themselves substance users ${ }^{4647}$ and are consequently at higher risk of substance use themselves.

The findings of this study emphasise the fact that healthrisk behaviours are more likely in population subgroups characterised by certain socioeconomic variables. It would therefore be useful to design selective prevention measures (programme designed for at risk groups) as well as the recommended universal approaches (programme designed for overall target population such as students) and indicated ones (programmes designed for people who are already experimenting with drugs) ${ }^{48}$ A good example of a successfully implemented prevention scheme is the Adolescent Transitions Program (ATP) $:^{49}$ this is a schoolbased programme that uses a tiered approach to provide prevention services for students in middle school and junior high school and their parents. A general intervention, intended for parents of all students in a school, establishes a Family Resource Room to engage parents, establish norms for parenting practices and disseminate information about the risks of problem behaviour and substance use in adolescence. A selective intervention level, called the Family Check-Up, offers family assessments and professional support to identify families at 


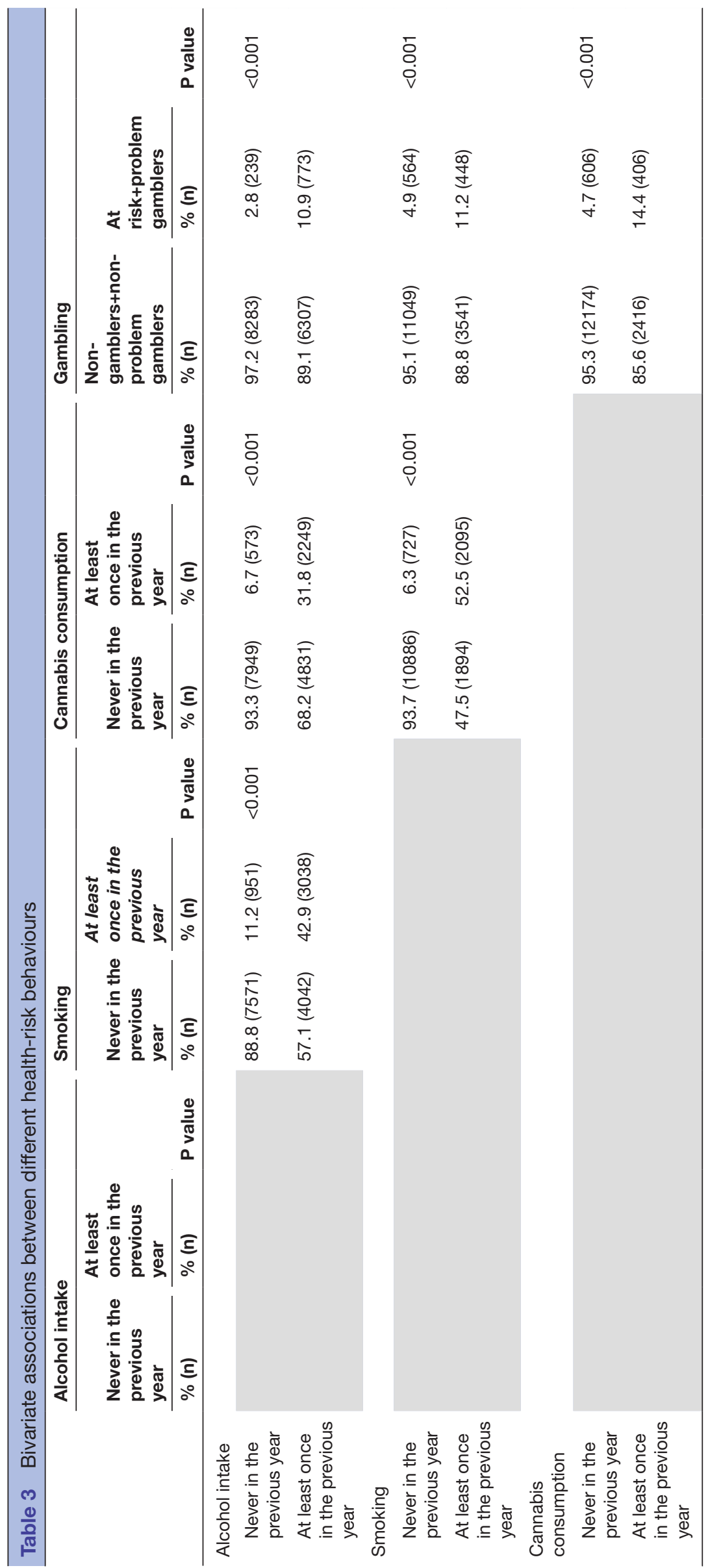

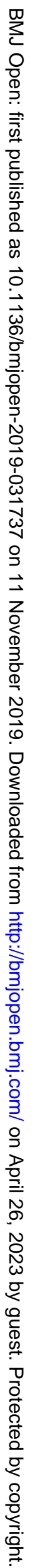




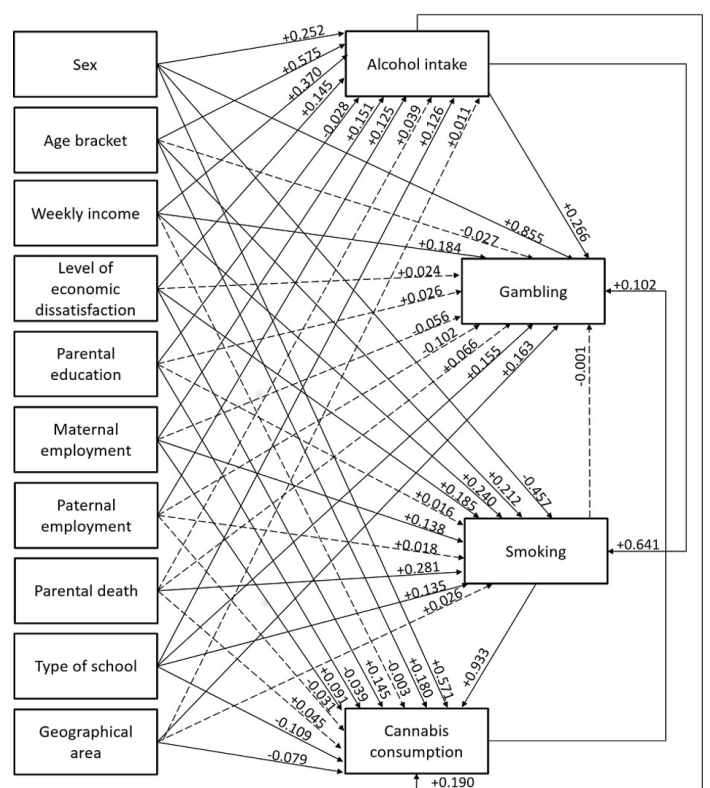

Figure 1 Pathway analysis of associations between gambling, substance use and demographic and socioeconomic factors.

risk of problem behaviour and substance use. The indicated level, the Parent Focus curriculum, provides direct professional support to help parents make the changes indicated by the Family Check-Up. The services may include behavioural family therapy, parenting groups or case management services. ${ }^{48}$ The longitudinal effects of the ATP through middle school and the first year of high school have been analysed and shown that random assignments to the school-based ATP were associated with a lower incidence of substance use by the first year of high school, even after controlling for prior substance use in middle school. ${ }^{49}$

\section{Limitations}

This study has a couple of limitations, primarily relating to the fact that our data were obtained from a sample of adolescents attending school. This means that those who dropped out of school at 16 years old (on completing their compulsory education in Italy) were not considered, so our sample was only representative of Italian school students. A second limitation lies in that our findings are based on self-reports and may be biased by respondents' under-reporting or over-reporting of their risk-taking behaviour. To mitigate this potential bias, we guaranteed respondents' anonymity and confidentiality.

\section{CONCLUSION}

This is one of the first studies to analyse the explanatory pathway connecting health-risk behaviours (such as gambling, alcohol drinking, smoking and cannabis consumption) with demographic and socioeconomic factors in adolescence. Clarifying the various determinants of the worrying phenomena of substance use and gambling in this age group is fundamental to the design of appropriate public health strategies and prevention measures in order to address and contain these widespread issues.

\section{Twitter Alessandra Buja @alessandrabuja}

Contributors $A B$ conceptualised the study, interpreted the data and drafted the manuscript. CM obtained funding, coordinated all study phases and approved the final manuscript as submitted. LM was involved in planning and supervising the work and approved the final manuscript as submitted. AM was involved in planning and supervising the work and approved the final manuscript as submitted. SP conceived, designed and directed the project. BG designed the data collection tools and coordinated and supervised data collection. PV carried out the statistical analyses and approved the final manuscript as submitted. AA carried out the statistical analyses and approved the final manuscript as submitted. GG drafted the manuscript and approved the final manuscript as submitted. VB critically reviewed and revised the manuscript. RP supervised the study, obtained funding and approved the final manuscript as submitted.

Funding The study was sponsored and financed by the Agenzia delle Dogane e dei Monopoli dello Stato.

Disclaimer The agency had no role in the design of the study, the collection, analysis and interpretation of the data, the writing of the manuscript or the decision to submit the paper for publication.

Competing interests None declared.

Patient consent for publication Not required.

Ethics approval This study was approved by the ethics committee of the Italian National Health Institute. The study complied with the Declaration of Helsinki and with Italian Law $n .196 / 2003$ on the protection of personal data. The questionnaires were anonymous, with no chance of individuals being identifiable. Consent to the students' participation was required first from the school director; then, all parents signed to their consent to the minors' participation in the survey.

Provenance and peer review Not commissioned; externally peer reviewed. Data availability statement Data are available on reasonable request.

Open access This is an open access article distributed in accordance with the Creative Commons Attribution Non Commercial (CC BY-NC 4.0) license, which permits others to distribute, remix, adapt, build upon this work non-commercially, and license their derivative works on different terms, provided the original work is properly cited, appropriate credit is given, any changes made indicated, and the use is non-commercial. See: http://creativecommons.org/licenses/by-nc/4.0/.

ORCID iDs

Alessandra Buja http://orcid.org/0000-0003-2216-3807

Giulia Grotto http://orcid.org/0000-0003-0562-2717

\section{REFERENCES}

1 Molinaro S, Canale N, Vieno A, et al. Country- and individual-level determinants of probable problematic gambling in adolescence: a multi-level cross-national comparison. Addiction 2014;109:2089-97.

2 Gutierrez A, Sher L. Alcohol and drug use among adolescents: an educational overview. Int J Adolesc Med Health 2015;27:207-12.

3 American Psychiatric Association. Diagnostic and statistical manual of mental disorders. 5th edn. Arlington, VA: American Psychiatric Publishing, 2013.

4 Jackson KM, Sher KJ, Schulenberg JE. Conjoint developmental trajectories of young adult alcohol and tobacco use. J Abnorm Psychol 2005;114:612-26.

5 Chambers RA, Potenza MN. Neurodevelopment, impulsivity, and adolescent gambling. J Gamb/ Stud 2003;19:53-84.

6 McGrath DS, Barrett SP. The comorbidity of tobacco smoking and gambling: a review of the literature. Drug Alcohol Rev 2009;28:676-81.

7 Tackett JL, Krieger H, Neighbors C, et al. Comorbidity of alcohol and gambling problems in emerging adults: a bifactor model conceptualization. J Gamb/ Stud 2017;33:131-47.

8 Cunningham-Williams RM, Cottler LB, Compton WM, et al. Taking chances: problem gamblers and mental health disorders--results from the St. Louis Epidemiologic Catchment Area Study. Am J Public Health 1998;88:1093-6. 
9 Crockford DN, el-Guebaly N. Psychiatric comorbidity in pathological gambling: a critical review. Can J Psychiatry 1998;43:43-50.

10 Cronce JM, Corbin WR. Effects of alcohol and initial gambling outcomes on within-session gambling behavior. Exp Clin Psychopharmacol 2010;18:145-57.

11 Soteriades ES, DiFranza JR. Parent's socioeconomic status, adolescents' disposable income, and adolescents' smoking status in Massachusetts. Am J Public Health 2003;93:1155-60.

12 Wen M, Van Duker H, Olson LM. Social contexts of regular smoking in adolescence: towards a multidimensional ecological model. $J$ Adolesc 2009;32:671-92.

13 Welte JW, Barnes GM, Tidwell M-CO, et al. The prevalence of problem gambling among U.S. adolescents and young adults: results from a national survey. J Gamb/ Stud 2008;24:119-33.

14 Kristiansen SG, Jensen SM. Prevalence and correlates of problematic gambling among Danish adolescents. Int J Soc Welf 2014;23:89-99.

15 Blinn-Pike L, Worthy SL, Jonkman JN. Adolescent gambling: a review of an emerging field of research. $J$ Adolesc Health 2010;47:223-36.

16 Martins SS, Storr CL, Lee GP, et al. Environmental influences associated with gambling in young adulthood. $J$ Urban Health 2013:90:130-40.

17 Buja A, Lion C, Scioni M, et al. SOGS-RA gambling scores and substance use in adolescents. J Behav Addict 2017;6:425-33.

18 Barnes GM, Welte JW, Hoffman JH, et al. Gambling and alcohol use among youth: influences of demographic, socialization, and individual factors. Addict Behav 1999;24:749-67.

19 Winters KC, Stinchfield RD, Fulkerson J. Toward the development of an adolescent gambling problem severity scale. J Gambling Stud 1993:9:63-84.

20 Poulin C. An assessment of the validity and reliability of the SOGSRA. J Gambl Stud 2002;18:67-93.

21 Peters EN, Nordeck C, Zanetti G, et al. Relationship of gambling with tobacco, alcohol, and illicit drug use among adolescents in the USA: review of the literature 2000-2014. Am J Addict 2015;24:206-16.

22 Muthen LK, Muthen BO. Mplus User's Guide. 5th edn. Los Angeles, CA: Muthen \& Muthen, 1998-2009.

23 Kline RB. Principles and practice of structural equation modeling. 3rd edn. New York, NY: Guilford Press, 2010.

24 Caldeira KM, Arria AM, O'Grady KE, et al. Risk factors for gambling and substance use among recent college students. Drug Alcohol Depend 2017;179:280-90.

25 Consiglio Nazionale delle Ricerche IFC- Instituto di Fisiologia Clinica. Consumi d'azzardo 2017. Available: https://www.epid.ifc. cnr.it/images/downloads/Report/Gioco/Consumi_azzardo_2017.pdf [Accessed 16 Apr 2019].

26 Governo Italiano. Relazione annualeal parlamentosullo stato delle tossicodipendenzein Italia. Available: http://www.politicheantidroga. gov.it/media/2153/relazione-al-parlamento_2017.pdf [Accessed 16 Apr 2019].

27 Barnes GM, Welte JW, Hoffman JH, et al. The co-occurrence of gambling with substance use and conduct disorder among youth in the United States. Am J Addict 2011;20:166-73.

28 Kandel D. Stages in adolescent involvement in drug use. Science 1975;190:912-4

29 Kandel D, Faust R. Sequence and stages in patterns of adolescent drug use. Arch Gen Psychiatry 1975;32:923-32.

30 Lynskey MT, Heath AC, Bucholz KK, et al. Escalation of drug use in early-onset cannabis users vs co-twin controls. JAMA 2003;289:427-33.
31 Darling H, Reeder Al, McGee R, et al. Brief report: disposable income, and spending on fast food, alcohol, cigarettes, and gambling by new Zealand secondary school students. J Adolesc 2006:29:837-43.

32 Farrell S, Manning WG, Finch MD. Alcohol dependence and the price of alcoholic beverages. J Health Econ 2003;22:117-47.

33 Keeler TE, Hu TW, Barnett PG, et al. Do cigarette producers pricediscriminate by state? an empirical analysis of local cigarette pricing and taxation. $J$ Health Econ 1996;15:499-512.

34 Bellis MA, Hughes K, Morleo M, et al. Predictors of risky alcohol consumption in schoolchildren and their implications for preventing alcohol-related harm. Subst Abuse Treat Prev Policy 2007;2:15.

35 Arillo-Santillan E, Lazcano-Ponce E, Hernandez-Avila M, et al. Associations between individual and contextual factors and smoking in 13,293 Mexican students. Am J Prev Med 2005;28:41-51.

36 Humensky JL. Are adolescents with high socioeconomic status more likely to engage in alcohol and illicit drug use in early adulthood? Subst Abuse Treat Prev Policy 2010;5:19.

37 Lemstra M, Bennett NR, Neudorf C, et al. A meta-analysis of marijuana and alcohol use by socio-economic status in adolescents aged 10-15 years. Can J Public Health 2008;99:172-7.

38 Agnew R, White HR. An empirical test of general strain THEORY* Criminology 1992;30:475-500.

39 Legleye S, Janssen E, Beck F, et al. Social gradient in initiation and transition to daily use of tobacco and cannabis during adolescence: a retrospective cohort study. Addiction 2011;106:1520-31.

40 Lacey RE, Zilanawala A, Webb E, et al. Parental absence in early childhood and onset of smoking and alcohol consumption before adolescence. Arch Dis Child 2018;103:691-4.

41 Steinberg L, Fletcher A, Darling N. Parental monitoring and peer influences on adolescent substance use. Pediatrics 1994;93:1060-4.

$42 \mathrm{Li} \mathrm{X}$, Stanton B, Feigelman S. Impact of perceived parental monitoring on adolescent risk behavior over 4 years. J Adolesc Health 2000;27:49-56.

43 Hsu Y-T, Kawachi I. Timing of family adversity during adolescence and its impact on alcohol and tobacco initiation: a longitudinal study among Taiwanese adolescents. Child Psychiatry Hum Dev 2019;50:257-67.

44 Shonkoff JP, Garner AS, Committee on Psychosocial Aspects of Child and Family Health. The lifelong effects of early childhood adversity and toxic stress. Pediatrics 2012;129:e232-46.

45 Sudraba V, Millere A, Deklava L, et al. Stress coping strategies of drug and alcohol addicted patients in Latvia. Procedia Soc Behav Sci 2015;205:632-6.

46 Anda RF, Whitfield CL, Felitti VJ, et al. Adverse childhood experiences, alcoholic parents, and later risk of alcoholism and depression. Psychiatr Serv 2002;53:1001-9.

47 Dube SR, Felitti VJ, Dong M, et al. Childhood abuse, neglect, and household dysfunction and the risk of illicit drug use: the adverse childhood experiences study. Pediatrics 2003;111:564-72.

48 Robertson EB, David SL, Rao SA. Preventing drug use among children and adolescents. In: A research-based guide for parents, educators, and community leaders. 2nd edn. Bethesda, MD: US Department of Health and Human Services, National Institute on Drug Abuse 2003 NIH Publication no 04-4212(A), 2003.

49 Dishion TJ, Kavanagh K, Schneiger A, et al. Preventing early adolescent substance use: a family-centered strategy for the public middle school. Prev Sci 2002;3:191-201. 